\title{
The ovarian-uterine vasculature in relation to unilateral endometrial growth in flying foxes (genus Pteropus, suborder Megachiroptera, order Chiroptera)
}

\author{
C. S. T. Pow ${ }^{*}$ and L. Martin ${ }^{\dagger}$ \\ Department of Physiology and Pharmacology, The University of Queensland, QLD 4072, Australia
}

\begin{abstract}
The ovarian-uterine vasculature was examined in three Australian species of flying fox (Pteropus scapulatus, P. poliocephalus and P. alecto). Vascular casts and histological sections were used to determine the relationship between the blood supply and the localized endometrial reaction, which occurs ipsilateral to the ovulating ovary. The ovarian artery coils extensively just cranial to the ovary, gives off a branch to the ovary and continues caudally as the major vessel supplying the cranial tip of the uterus, where it anastomoses with the smaller uterine artery. The coil of the ovarian artery is completely enclosed by a venous sinus that drains the cranial pole of the ovary. The ovary is heavily encapsulated, with primordial follicles restricted to the caudal pole; thus, the corpus luteum is completely internal and placed cranially, close to the coil of the ovarian artery. This arrangement would allow countercurrent or crosscurrent transfer of ovarian steroids from ovarian vein to ovarian artery and on to the cranial tip of the ipsilateral uterine horn. The steroids could thus reach high concentrations locally and generate localized endometrial growth. Cranial to the coil, the ovarian artery is enclosed in a venous sinus that derives from uterine as well as ovarian veins. This would allow countercurrent transfer of bioactive substances from uterus to ovary.
\end{abstract}

\section{Introduction}

The order Chiroptera expresses an extremely high incidence of female reproductive asymmetry, which is defined as a unilateral dominance of either one ovary, one uterine horn or both (Wimsatt, 1975, 1979). In the suborder Microchiroptera, several diverse patterns of asymmetry have been documented, in which one or other ovary and the ipsilateral or contralateral uterine horn is non-functional. The suborder Megachiroptera is thought to express only the simplest form of asymmetry namely nonrandom alternation of ovulation between ovaries in successive reproductive cycles ('the Pteropid pattern'; Wimsatt, 1975).

Members of the megachiropteran genus Pteropus (flying foxes) are seasonal breeders and monovulatory (Baker and Baker, 1936; Marshall, 1948; Nelson, 1963; Towers and Martin, 1985; Martin et al., 1987). Both ovaries and both horns of the duplex uterus are functional. Pregnancy occurs with equal frequency in the right and left horns, and it has been suggested that ovulation alternates from side to side in successive breeding seasons (Marshall, 1949; Nelson, 1963). Preimplantation endometrial growth and development is limited to the uterine horn ipsilateral to the ovulating ovary (Wimsatt, 1975).

*Present address: California Regional Primate Research Center, Davis, CA 95616-8542, USA.

${ }^{\dagger}$ Correspondence.

Received 15 June 1993
Marshall (1949), who first described this 'asymmetric', or 'unilateral' endometrial reaction in the Indian flying fox Pteropus giganteus, stated that growth of the endometrium was restricted to the cranial tip of the uterine horn adjacent to the ovulating ovary, with the caudal region of the horn and entire contralateral horn remaining relatively undeveloped. He considered that a localized endometrial reaction developed only after ovulation, with formation of a functional corpus luteum. In Australian flying foxes, unilateral growth first occurs as the preovulatory follicle forms and involves the full length of the uterine horn, its later development and form being dependent on formation of a corpus luteum (L. Martin and P. A. Towers, unpublished).

Several theories have been proposed to explain the localized endometrial reaction seen in Pteropus and comparable localized oviductal and uterine reactions observed in Microchiroptera and some marsupials (Marshall, 1949, 1953; Gopalakrishna and Murthy, 1960; von der Borch, 1963; Rasweiler, 1972, 1978; De Bonilla and Rasweiler, 1974). The most widely favoured theory is that of local countercurrent transfer of ovarian hormones from the ovarian vein or lymphatics to the artery supplying the ipsilateral uterus or oviduct (De Bonilla and Rasweiler, 1974; Lee and O'Shea, 1977; Rasweiler, 1978; Wimsatt, 1979). The present anatomical study of the reproductive tract and associated vasculature in three species of Australian flying fox was undertaken to elucidate the possible relationship between the blood supply and localized 
endometrial growth. A brief account of our results has been published previously (Pow and Martin, 1987).

\section{Materials and Methods}

\section{Animals}

The Little-red flying foxes ( $P$. scapulatus) used for the vascular casts had been caught in March 1986, approximately $400 \mathrm{~km} \mathrm{NNW}$ of Brisbane. They were subsequently housed in large open cages at the University Veterinary Science farm and fed daily with a variety of chopped fruit plus full cream milk powder. Water was provided ad libitum. Grey-headed flying foxes (P. poliocephalus), which were used for histological studies of the ovarian-uterine vasculature, were shot in the wild approximately $125 \mathrm{~km} \mathrm{SW}$ of Brisbane, or were taken from power lines in suburban Brisbane on which they had just been electrocuted. Other histological material came from (1) P. poliocephalus and Black flying foxes ( $P$. alecto) shot in the wild at various points around Brisbane for other studies (Towers and Martin, 1985), and (2) individuals from successful captive breeding colonies of $P$. poliocephalus, $P$. alecto and $P$. scapulatus, maintained from 1987 to the present. The method of collection did not have any obvious or marked effect on the vasculature of the reproductive tract.

\section{Vascular casts}

Vascular casts were prepared in late 1986 and early 1987 from three immature, three adult non-pregnant, one earlypregnant and one in which abortion took place in late pregnancy $P$. scapulatus females and from one postpartum (24 h) P. poliocephalus female.

Animals were killed with an overdose of pentobarbitone sodium (162.5 mg kg-1; Arnolds of Reading, Peakhurst) injected i.p. Ventral longitudinal midline incisions were made through the skin and body wall. The abdominal skin and body wall were reflected to expose the gut. Careful manipulation of the gut enabled the uterine horns and ovaries to be located and examined visually. Care was taken not to touch the reproductive organs or associated blood vessels. The thoracic cavity was then opened and the descending aorta cannulated with SV6I vinyl tubing, tied in position with cotton.

Where both the arterial and venous systems were perfused, the vasculature was flushed with isotonic saline at $37^{\circ} \mathrm{C}$, via the aortic cannula, using a $10 \mathrm{ml}$ syringe and a 21 gauge needle. An incision was made in the right atrium to allow blood and perfusate to escape. Flushing was continued until the escaping perfusate appeared to be clear of blood. The inferior vena cava was then cannulated in a similar manner and orange microfil (Canton Biomedical Products Inc, Boulder, $\mathrm{CO}$ ) was infused slowly using a $5 \mathrm{ml}$ syringe and 21 gauge needle and, as far as possible, a constant manual pressure. Filling of the venous vasculature was monitored visually under a dissecting microscope. Infusion was stopped when major vessels began to distend. The cannula was then tied off.

The arterial circulation was then perfused with latex (Dunlop Rubber Co, Melboume) via the aortic cannula, using the same procedure as for the venous perfusion. Filling was again monitored visually under a dissecting microscope and stopped as major vessels started to distend. The cannula was then tied off and the whole specimen placed at $4^{\circ} \mathrm{C}$ overnight to allow the injection media to set. The reproductive tract and associated blood vessels were dissected out, fixed in Bouin's fluid for $24 \mathrm{~h}$, dehydrated in ascending grades of alcohol and cleared in benzyl benzoate (Ajax Chemicals, Sydney).

Since initial preparations had demonstrated that microfilled veins obscure the view of the arteries, only the arterial system was perfused in most cases. In these bats, the aorta was cannulated as before, but the vessels were not flushed with saline before the infusion of latex via the aortic cannula. This procedure allowed blood to remain in the veins so that they could be visualized, while allowing a good view of the perfused arteries after fixation, dehydration and clearing.

\section{Histology}

Freshly dissected tissues were fixed overnight in Bouin's fluid and stored in $70 \%$ aqueous ethanol until processing. After dehydration in ascending concentrations of ethanol and clearing in toluene, tissues were vacuum-embedded in paraffin wax. Serial sections cut at a thickness of $7 \mu \mathrm{m}$ in various planes were stained with Gomori's trichrome stain or Mayer's haematoxylin and eosin.

\section{Results}

\section{General}

Apart from vascular casts and histological sections prepared specifically to explore the ovarian-uterine vasculature, the tract was examined (1) visually in situ immediately after killing, in $>30$ females of various ages from long-term breeding colonies of the three Pteropus species, and (2) histologically, by serial frontal and transverse sections of the tract, in $>70$ females of the three species shot in the wild (Towers and Martin, 1985) or from our breeding colonies.

Essentially the same ovarian-uterine vascular anatomy was seen in all three species, although with some difference in overall size between $P$. scapulatus and the two larger species. Vascular casts showed variation between individual $P$. scapulatus females in the anatomy of some vessels, but no marked differences in the major vessels, beyond altered diameter associated with altered reproductive state. The same was true of the anatomy of the reproductive tract.

\section{The reproductive tract}

A complete reproductive tract dissected from an adult non-pregnant female $P$. scapulatus immediately after killing (Fig. 1) illustrates the size and relationships of the uterus, ovary, bursa, oviduct, ligaments and associated blood vessels. This specimen was pinned out to give a better display of the blood vessels in the ovarian mesentery: each ligament was pinned directly cranial and the mesenteric blood vessels were pinned craniolaterally. In situ, the ligament runs craniolaterally, 

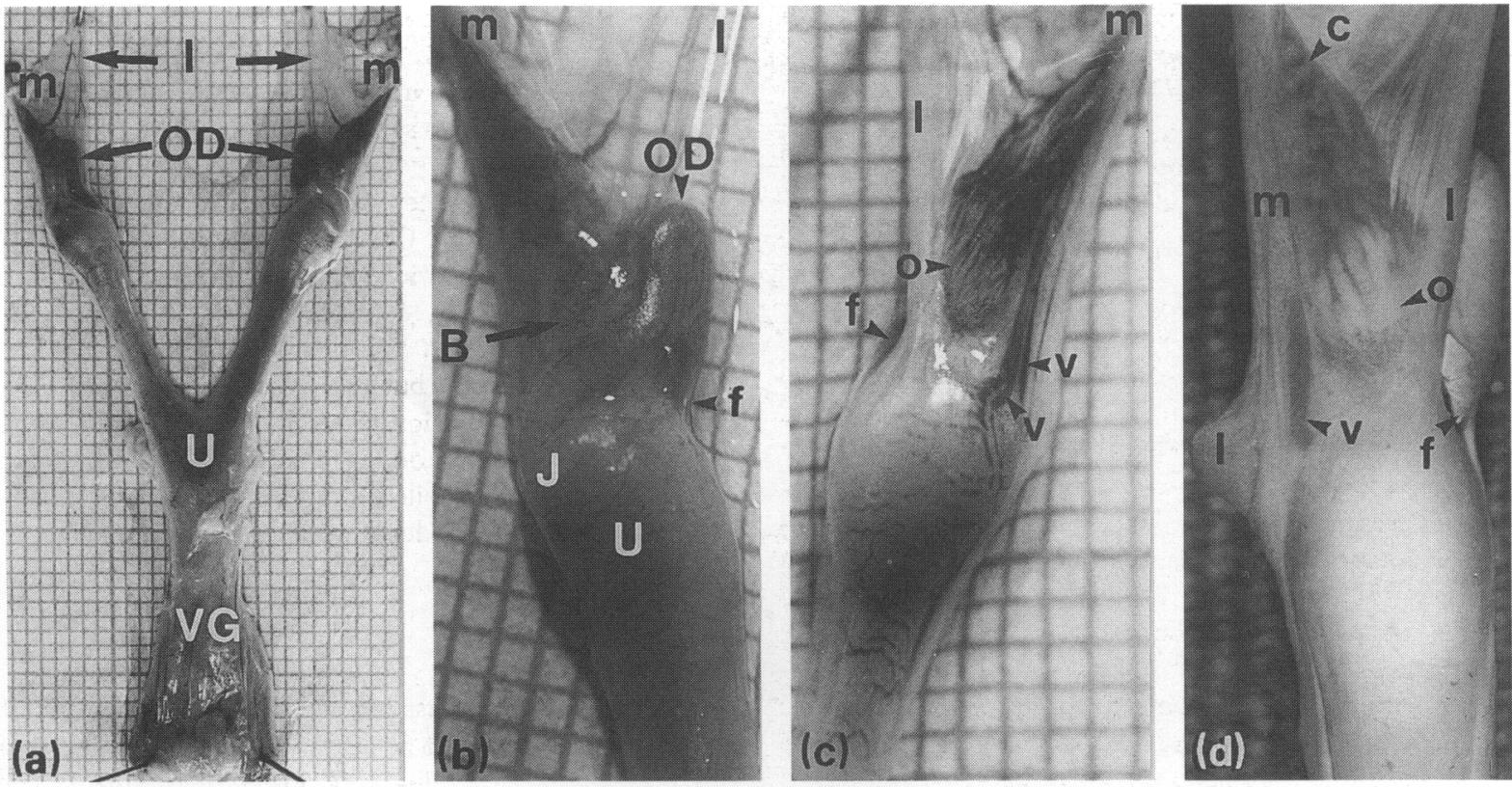

Fig. 1. The freshly dissected reproductive tract from an adult non-pregnant female Pteropus scapulatus. (a) Ventral view of whole tract. (b, c) Closer views of ventral and dorsal aspects, respectively, of the cranial tip of the right uterine horn and associated structures. (d) Closer view of the dorsal aspect of the cranial tip of the left uterine horn and associated structures after fixation. B: bursa; c: coil of ovarian artery; f: fimbria; J: utero-tubal junction; l: ligament; m: mesentery; o: ovary; OD: oviduct; U: uterus; v: vein; VG: vagina. Small squares are $\mathrm{mm}$.

crossing ventrally over the mesenteric blood vessels that run craniomedially.

Both horns of the duplex uterus are slightly swollen at the cranial pole. The oviduct follows a simple curve from the ventrolateral utero-tubal junction to a point just cranial to the ovary, returning caudally to the fimbria, which is attached to both ovary and ligament and protrudes through a slit in the bursa to the peritoneal cavity. Caudally, the ovary is attached to the ligament and cranial tip of the uterus. In the ventral view, the ovary is hidden by its enclosing bursa. In the dorsal view, veins can be seen draining cranially from the smoothly ellipsoid ovary and appear to enclose a coiled artery. One or more veins run cranially from the uterus towards the ovarian venous drainage and a large artery appears to be closely associated with these uterine veins.

\section{The ovarian and uterine arteries}

The major blood vessels of an adult non-pregnant female $P$. scapulatus that had received an arterial infusion of white latex and a venous infusion of orange microfil are shown (Fig. 2a and $c-g)$. Both ovarian arteries rise ventrally from the descending abdominal aorta about $1 \mathrm{~cm}$ caudal to the renal arteries. They usually arise from a common stem and each gives off branches to the ipsilateral kidney capsule and surrounding tissue while running caudally close to the inferior medial side of the kidney.

Immediately before reaching the ovary and oviduct, each ovarian artery forms a tight coil (Fig. 2a, b, e-g). A separate branch (or, occasionally, branches) stems from the caudal region of this coil to supply the ipsilateral ovary (Fig. 3). Other smaller vessels branch off from points throughout the coil to feed the oviduct. The ovarian suspensory ligaments, which run cranially to attach to the dorsal body wall lateral to the kidney, are each vascularized by a small artery that appears to run cranially from the ipsilateral coil. Each ovarian artery continues caudally, running dorsal to the isthmus of the oviduct to anastomose with the uterine artery at the cranial tip of the horn (Fig. 2e, g).

In four preparations, a small artery (marked b in Figs 2, 3 and 4) branched from the ovarian artery cranial to the coil and ran caudally to join the uterine artery at the cranial tip of the uterine horn, close to the anastomosis of the ovarian and uterine arteries.

The abdominal aorta terminates by branching into four prominent arteries (Fig. 2a, b). Two of these, the left and right common iliacs, then divide into the internal and external iliacs. The internal iliacs run dorsal to the duplex uterus and give off branches to the urinary bladder and vagina, and provide the uterine arteries. Each uterine artery runs cranially and dorsolaterally in the mesometrium, giving off small branches to the caudal regions of the uterus.

At the point of anastomosis of the uterine and ovarian arteries, extensive branches provide a rich arterial supply to the cranial tip of the uterus. Figure 3 shows sketches of the vessels supplying the ovary and cranial tip of the uterus in vascular casts from two non-pregnant $P$. scapulatus females. In all such preparations, each ovarian artery had a larger diameter than the corresponding uterine artery. This is also evident in a preparation from an early-pregnant $P$. scapulatus female (Fig. 4). It is also apparent in this specimen that the major arterial supply to the placenta comes from the ovarian rather than the uterine artery. Visual examination of the unfixed uterus and placenta immediately after killing in two near-term pregnant $P$. poliocephalus females confirmed this to be so. In late 

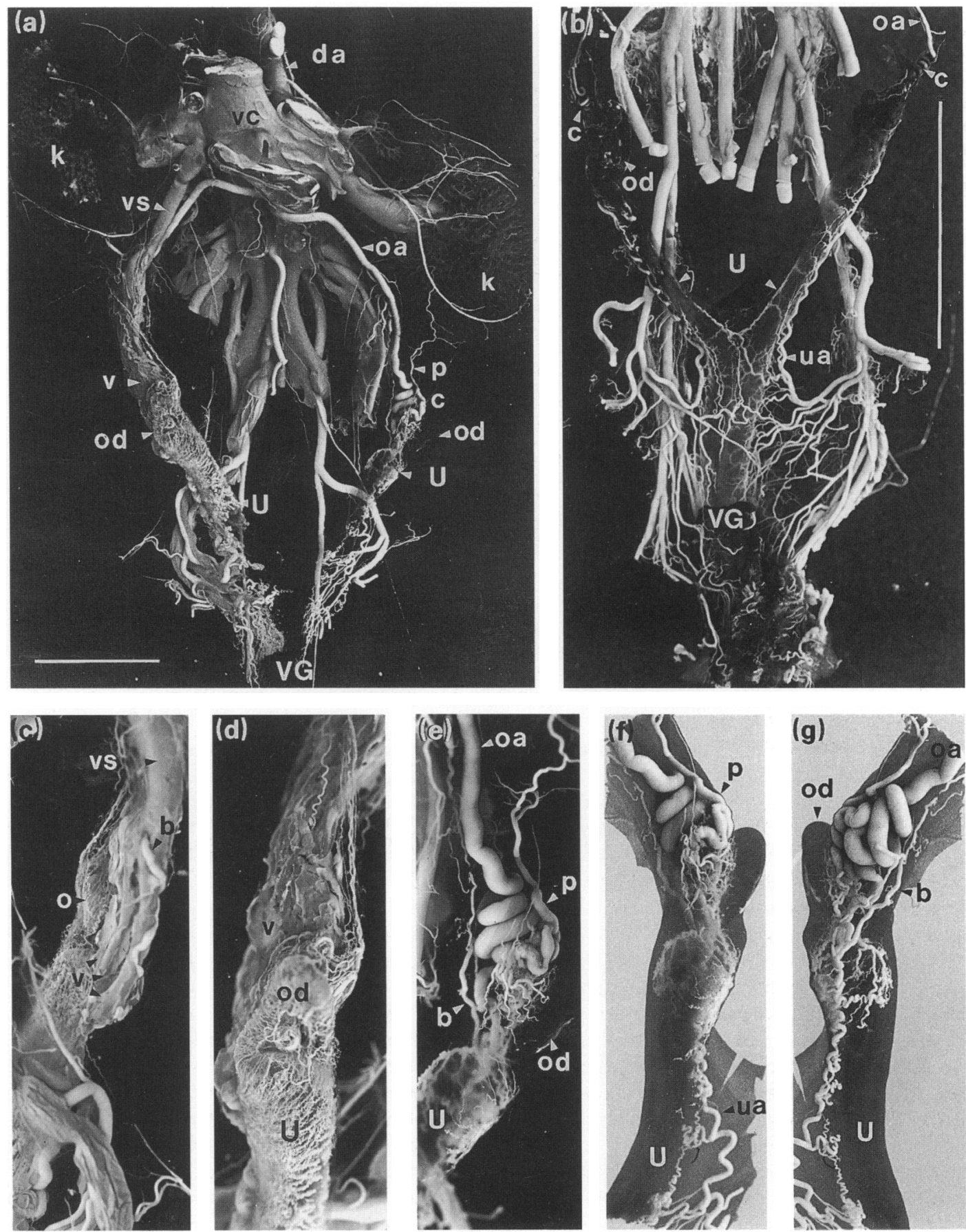

Fig. 2. Vascular casts from a non-pregnant female Pteropus scapulatus. Tracts were fixed in Bouin's fluid and cleared in benzyl benzoate. (a) Ventral view of a preparation in which veins were injected with orange microfil and arteries with white latex (scale bar represents $1 \mathrm{~cm}$ ). On the left side, only the major arteries filled with casting material; on the right, the arterial system appeared to fill completely with latex, while only major veins contained microfil. On the left, the ovarian artery coils immediately cranial to the ovary; on the right the coil is obscured by veins. (b) Dorsal view of a preparation from an immature female in which only the arteries were injected with white latex (scale bar represents $1 \mathrm{~cm}$ ). The origin of the uterine artery is clearly visible. (c) Dorsal and (d) ventral aspects of the cranial tip of the right uterine horn and associated tissues of preparation (a). Two large veins run cranially from the uterus and appear to combine with ovarian veins in a common vessel that hides the ovarian artery. (e) Ventral, ( $\mathrm{f}$ ) lateral and $(\mathrm{g}$ ) dorsal aspects of the cranial tip of the left uterine horn and associated tissues of preparation (a). Vessel $\mathrm{p}$ [also in (a) J, which joins the caudal region of the coil of the ovarian artery, is derived from an artery supplying the kidney capsule. This in turn branched from an artery originating from the dorsal aorta just cranial to the renal artery and passing close to the adrenal vein before branching to the kidney capsule. This arrangement was not seen in any other preparation. Vessel $b$ branched from the ovarian artery just cranial to the coil and ran directly to the uterine artery in the cranial tip of the uterine horn. Such a vessel was seen in three other tracts (see Figs 3 and 4). c: coil of ovarian artery; da: dorsal aorta; k: kidney; o: ovary; oa: ovarian artery; od: oviduct; U: uterine horn; ua: uterine artery; v; vein; vc: vena cava; VG: vagina; vs: venous sinus. 

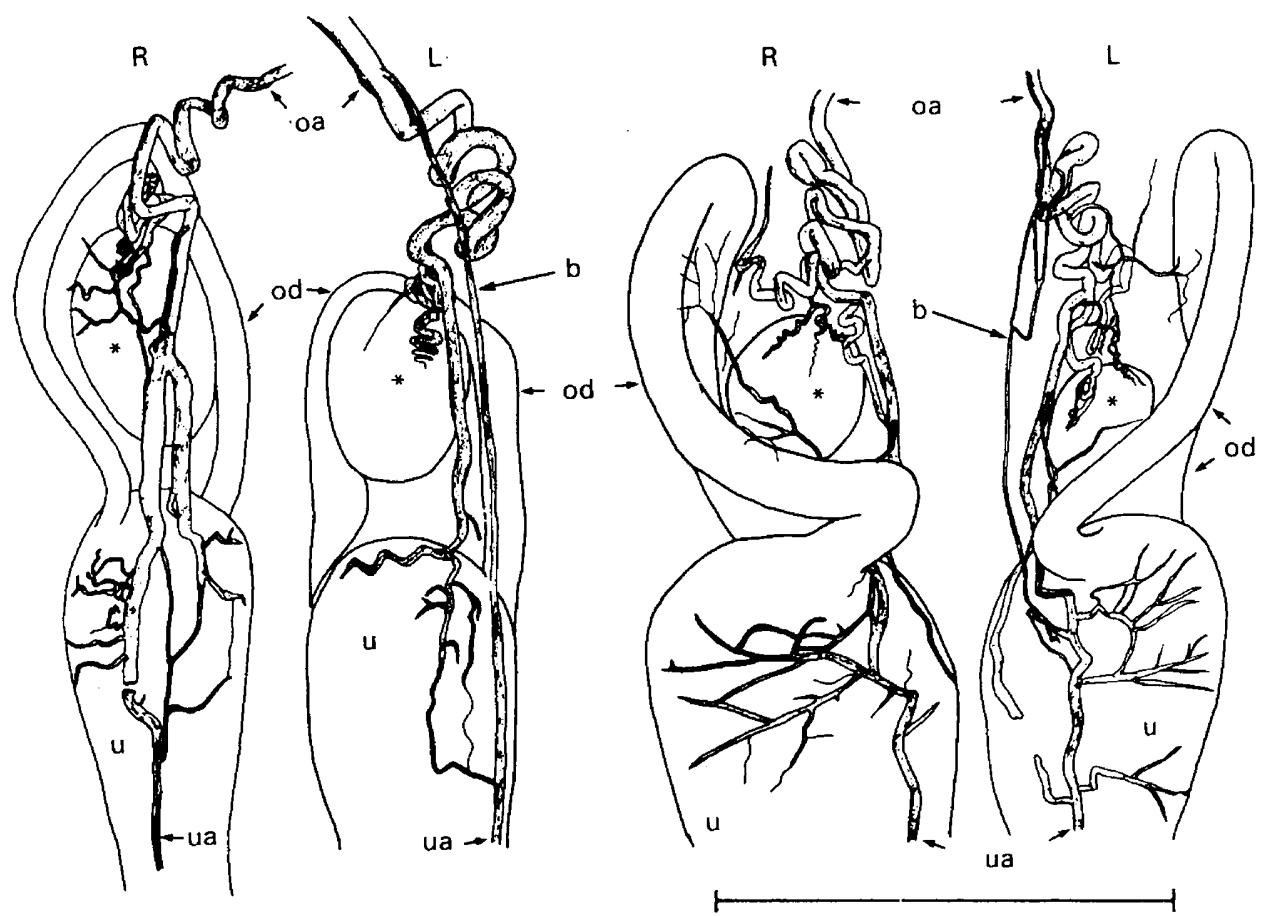

Fig. 3. The dorsal aspect of vascular casts of the cranial tips of right $(R)$ and left $(L)$ uteri and associated structures from two non-pregnant Pteropus scapulatus females, in which only the arteries were injected (Scale bar represents $5 \mathrm{~mm}$ ). b: The vessel that runs from the ovarian to uterine artery, bypassing the coil in the former. Major vessels supplying the ovary $\left(^{*}\right)$ leave the ovarian artery caudal to the coil. oa: ovarian artery: od: oviduct, u: uterus; ua: uterine artery.

pregnancy, the discoid placenta is centred on the utero-tubal junction and the ovarian artery provides the major supply, with relatively little input apparent from the uterine artery.

\section{The ovarian and uterine veins}

In the first vascular cast preparation, in which both veins and arteries had been infused, only the veins of the right side of the tract filled with microfil. Comparison of the two sides [Fig. 2c, d (right) versus $\mathrm{e}-\mathrm{g}$ (left)] shows that the major ovarian and uterine veins run cranially and appear to enclose the coil of the ovarian artery and much of that artery, cranial to the coil. Enclosure of the ovarian artery within a venous sinus is clearly shown in the vascular cast from the early-pregnant $P$. scapulatus female in which the veins were left uninfused to allow relatively unimpeded views of the arterial vessels (Fig. 4). This sinus encloses the ovarian artery for approximately a third of its length as it runs cranially. The vessels then separate, the left venous sinus joining the left renal vein and the right venous sinus draining directly into the common inferior vena cava.

Major veins draining the cranial tip of the uterus also run cranially and in vascular cast preparations (Fig. 2c, d) appear to meet and join with the ovarian vein at a point level with the middle of the arterial coil, or just cranial to it. The caudal region of each uterine horn is drained by a vein that follows the uterine artery caudally, in the mesometrium, to meet veins draining the vagina (not illustrated).

The enclosure of the ovarian artery by ovarian and uterine veins was also apparent in unfixed tracts of non-pregnant and late-pregnant bats examined shortly after killing. It can be seen in the unfixed tract (Fig. I) that the ovary displays prominent veins that drain cranially and appear to enclose a coiled artery.

\section{Histological examination of the ovarian-uterine vasculature}

The exact relationship between the ovarian artery and the ovarian and uterine veins was investigated more thoroughly by taking serial transverse sections in the three species of Pteropus, through the ovarian artery and associated veins, from a level well cranial to the arterial coil to a level close to the anastomosis of the ovarian and uterine arteries.

Cranial to the arterial coil, the ovarian artery is completely enclosed by a single venous sinus (Fig. 5a). At this level the sinus is derived from both ovarian and uterine veins. In some sections the artery runs in the wall of the sinus, in others it appears to lie completely free in the lumen, and in some it is suspended in the lumen of the sinus by strands of connective tissue.

The artery can be distinguished by its thick layer of smooth muscle (tunica media) and internal elastic lamina (Fig. 5a). The vein appears to possess only a thin wall. The arterial outer connective tissue tunica adventitia is not clearly demarcated from the tunica media by an external elastic lamina, nor is the tunica adventitia of the artery distinguishable from that of the vein. Thus, the artery appears to be enclosed by a single thick connective tissue sheath. This sheath covers the artery in varying thickness along its length and through the coil, and is 

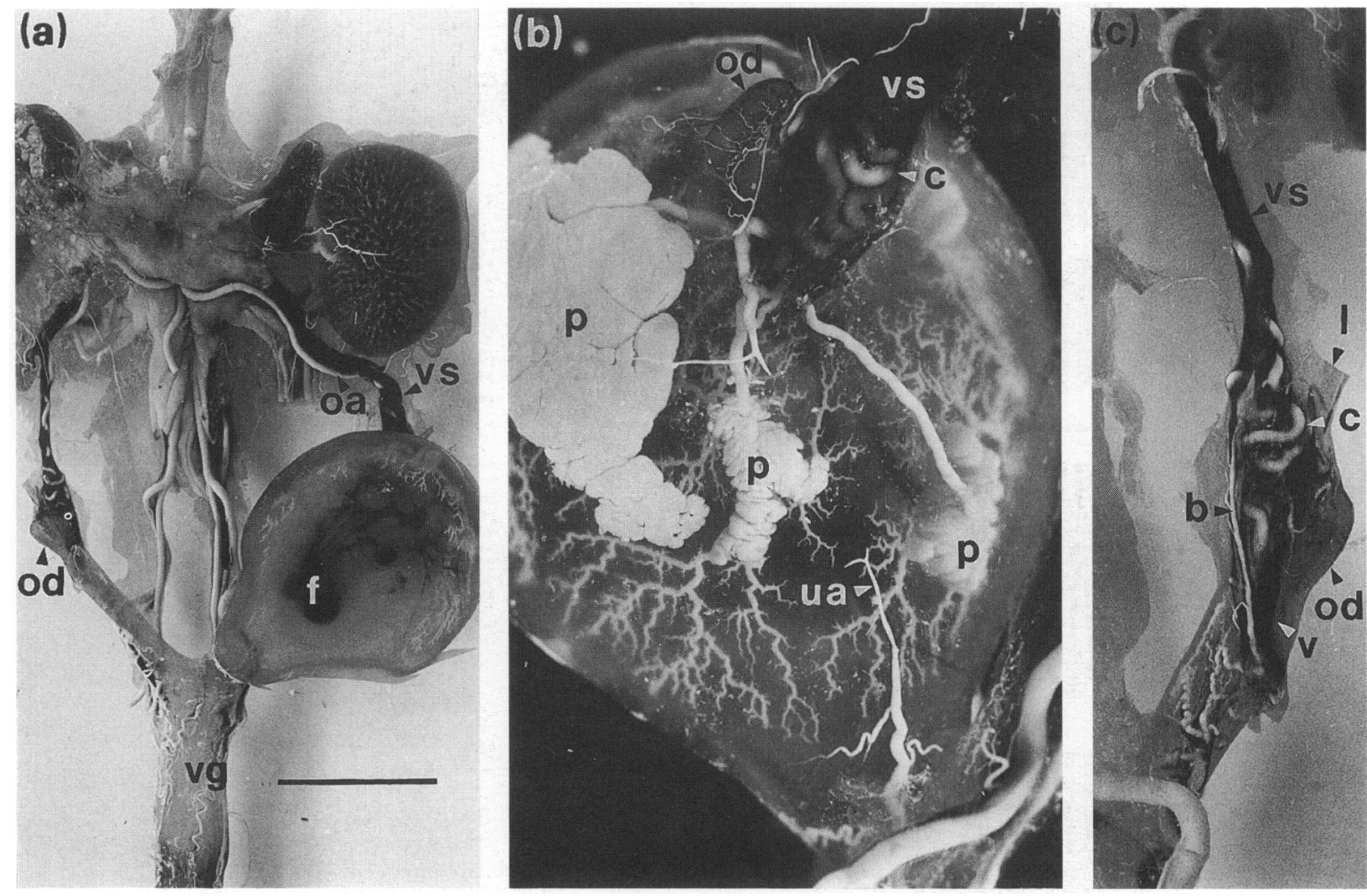

Fig. 4. Vascular cast from an early-pregnant Pteropus scapulatus female in which only the arteries were injected. The tract was fixed in Bouin's fluid and cleared in benzyl benzoate. (a) Ventral view of the whole reproductive tract and associated blood vessels (scale bar represents $1 \mathrm{~cm}$ ). (b) Close-up dorsal view of gravid uterus and the major blood vessels, clearly showing the enclosure of the coiled ovarian artery within a large venous sinus. (c) Close-up dorsal view of the non-gravid uterus and the major blood vessels. b: vessel that runs from the ovarian to uterine artery, bypassing the coil in the former; c: coil of ovarian artery; f: fetus; l: ligament; oa: ovarian artery; od: oviduct; p: placenta; ua: uterine artery; v: vein; vg: vagina; vs: venous sinus

a major factor determining the absolute distance between the arterial and venous lumina.

Transverse sections through the most cranial part of the coiled section of the ovarian artery show it to be enclosed in a single venous sinus. However, closer to the ovary the sinus is divided into two: the one enclosing the coil originates primarily from the ovarian venous drainage; and the other more lateral one originates exclusively from the uterine venous drainage (Fig. 5b-d). At this level, sections through the coil of the ovarian artery sometimes displayed up to eight crosssections, all completely enclosed by the venous sinus. Connective tissue strands run from the sheath of the coiled artery to the surrounding sinus wall, thereby 'suspending' the coil in the sinus. Serial sections taken caudally through the arterial coil revealed that the ovarian sinus enclosing the coil remains distinct from the uterine sinus. Towards the caudal end of the coil, arterial branches were traced feeding into the ovary, and veins draining the ovary were seen running into the ovarian sinus (Fig. $5 \mathrm{c}$ ). Caudal to the coil, the ovarian artery continued towards its anastomosis with the uterine artery, enclosed in one of the veins (or venous sinuses) originating from the cranial tip of the uterus (Fig. $5 \mathrm{~d}$ ).

Some of the above relationships are also apparent in the sketches of Fig. 3 and frontal sections of the tract (Fig. 5e, f). The frontal sections show the relationship of the ovarian- uterine vasculature to the ovary and neighbouring tissues. The ovary is unusual in that it is attached to the uterus by a very short ligament (Fig. 5e). It is also enclosed in a bursa and completely encapsulated so that the preovulatory follicle and corpus luteum remain totally internal. Another striking feature is the restriction of primordial follicles to a distinct zone at the caudal pole of the ovary, close to the ovarian-uterine ligament (Fig. 5e, f). Thus, follicle growth and subsequent development of the corpus luteum are directed cranially, the corpus luteum coming to lie close to the coil of the ovarian artery, with veins from the corpus luteum appearing to drain immediately onto it.

\section{Discussion}

Marshall (1949), who first described asymmetric endometrial development in Pteropus and attributed it to progesterone, noted that hormones usually flow from an active ovary into the bloodstream and become distributed equally to both uterine horns. He considered it unlikely that follicular fluid released at ovulation could directly prime the endometrium via the fallopian tube, but suggested that a nervous reflex arc between ovary and uterus might cause vasodilatation and unequal distribution of progesterone. 

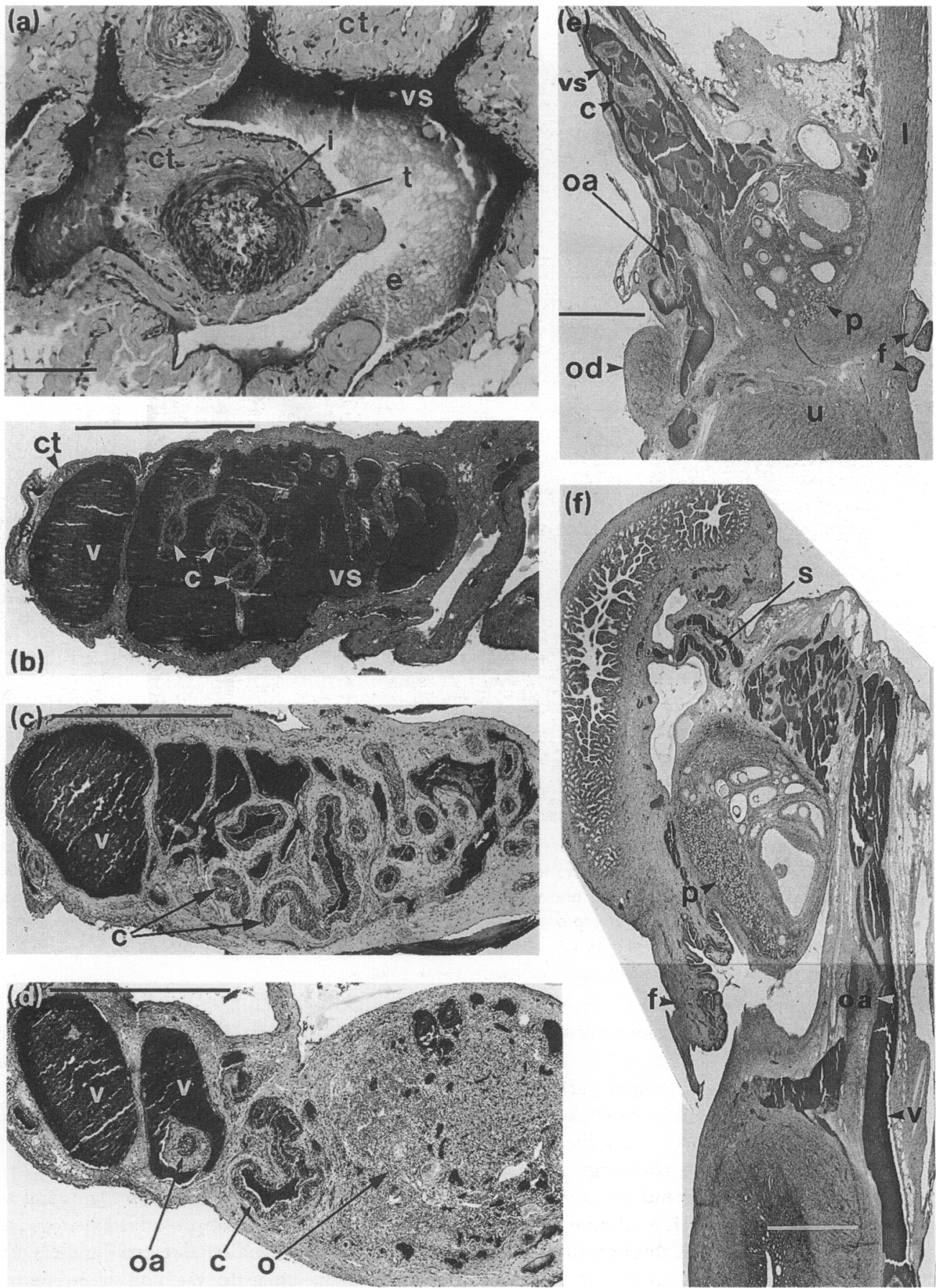

Fig. 5. Histological sections (at a thickness of $7 \mu \mathrm{m}$ ) of the ovary and associated vasculature of Pteropus females. (a-d) Transverse sections (Gomori's trichrome) at various levels cranial to the ovary in an adult female P. scapulatus and progressing caudally to the cranial pole of the ovary. Blood vessels filled with erythrocytes (e) appear near-black to black. (a) Section cranial to the coil of the ovarian artery. The artery is completely enclosed in a single venous sinus derived from both uterine and ovarian veins. The artery is joined to the wall of the sinus by connective tissue strands; in other sections it appears to lie completely free in the lumen of the sinus (scale bar represents $100 \mu \mathrm{m}$ ). (b) Section through the cranial region of the coil of the ovarian artery (scalebar represents $1 \mathrm{~mm}$ ). In this specimen, the outermost vein on the left, which derives from the uterus, remains separate at this level. Thus, the coil appears to be enclosed in a sinus that derives primarily from the ovary. In other specimens this outer vein joins more caudally with the ovarian venous sinus so that the cranial region of the coil is enclosed in a single sinus. (c) Section taken just cranial to the ovary: the main coil of the ovarian artery is in the centre; the smaller arteries to the right supply the ovary and are interspersed with veins draining the ovary. (d) Section at the cranial capsule of the ovary. The ovarian artery completes its coil and proceeds caudally to the uterus completely enclosed in a uterine vein. $(e, f)$ Frontal sections (haematoxylin and eosin) of tracts that were fixed with the ligament and ovarian vessels pinned out as shown in Fig. 1 (scalebar represents $1 \mathrm{~mm}$ ). (e) Section from an adult female P. poliocephalus, showing attachment of the left ovary to the ligament and uterus, junction of the uterine vein with the sinus draining the ovary and enclosure of the ovarian artery by the former vessels. (f) Right ovary and associated structures from an adult female $P$. alecto, showing the relationship of the ovary, oviduct, uterus and associated vessels. Vessels supplying the oviduct are marked [s]; the tissue joining the ovary and uterus has broken. Primordial follicles are restricted to a zone close to the junction of ovary, ligament, oviduct and uterus. c: coil of ovarian artery; ct: connective tissue; f: fimbria; $i$ : internal elastic lamina; 1: ligament; o: ovary; oa: ovarian artery; od: oviduct; p: primordial follicles; t: tunica media; u: uterus; $\mathrm{y}$; uterine vein; vs: venous sinus. 
Marshall (1953) noted that ovary and uterus are joined by a short isthmus, and that follicles develop within $1.0-1.4 \mathrm{~mm}$ of the endometrium while the corpus luteum develops within $1.5-1.8 \mathrm{~mm}$. He observed that 'unmistakable thin-walled vessels' traversed the isthmus, but that they were not organized into a system as elaborate as the hypophysial portal. He speculated that ovarian progesterone might pass directly to the uterus via these vessels or 'lymphatics and tissue spaces'. Gopalakrishna and Murthy (1960), who described the ovarianuterine junction in Cynopterus, stated that progestational changes appear only in the uterine horn ipsilateral to the ovulation. Like Marshall (1953) they noted that the ovary was enclosed by a complete capsule and connected to the uterus by a tissue bridge and 'small blood vessels which can be traced to the ovarian cortex on ... one side and ... endometrium on the other'. They suggested that this 'direct vascularised connection between ... ovary and ... uterine cornu' might short-circuit 'progesterone directly into the ... uterine cornu across the connective tissue bridge'.

It is clear that the vessels of Marshall (1953) and Gopalakrishna and Murthy (1960) do not correspond to the ovarian vascular complex that is described here for Pteropus. Moreover, we failed to find any vessels like those described by these workers, despite examining many sets of serial sections through the ovarian-uterine connective tissue isthmus of Pteropus.

When reviewing reproductive asymmetry and unilateral pregnancy in Chiroptera, Wimsatt (1979), argued that since the uteri of bats respond to gonadal steroids like other mammalian uteri, localized unilateral reactions implied the existence of local pathways whereby ovarian steroids directly influence the ipsilateral endometrium by virtue of unilateral sensitivity of the tissue to hormonal stimuli, unilateral delivery of the hormone to the target tissue, or unilateral inhibition of the target tissue. Given the lability of the unilateral endometrial response in Pteropus, Wimsatt hypothesized special vascular arrangements that would permit countercurrent exchange of steroid hormones or other diffusible substances between ovarian or uterine venous and lymphatic vessels and arterial branches supplying the ipsilateral uterus.

The ovarian vascular complex described above for Pteropus appears to satisfy Wimsatt's hypothesis. In particular, it could allow countercurrent or crosscurrent transfer of ovarian hormones to the ipsilateral endometrium: hormones released into the ovarian venous sinus would pass into the enclosed and coiled ovarian artery, and then into the ipsilateral uterine horn by way of the anastomosis with the uterine artery.

Such local circulation might explain why peripheral plasma concentrations of progesterone fail to rise dramatically after development of a corpus luteum in $P$. poliocephalus (Towers and Martin, 1985). If luteal progesterone were sequestered to, and metabolized to inactive compounds by the endometrium, as in rodents (Clark, 1973, 1974, 1975), substantial local increases in luteal secretion would have little effect on the peripheral concentration and the contralateral endometrium would remain unaffected.

The Pteropus ovarian vascular complex could also facilitate countercurrent transfer of bioactive substances from the uterus to the ipsilateral ovary, comparable with that of uterine $\mathrm{PGF}_{2 \alpha}$ in ewes (McCracken et al., 1972; Land et al., 1976). The venous sinus, which encloses the ovarian artery for much of its course cranial to the ovary, derives from uterine as well as ovarian veins. This would allow material of uterine origin to pass into the arterial blood and then into the ovary. The mechanisms controlling transfer of low molecular weight substances between blood vessels in countercurrent exchange have not been established. However, the consensus is that lipophilic substances, such as steroids and prostaglandins, which are thought to pass easily through cells, diffuse passively down a concentration gradient (Einer-Jensen, 1988). Passage of peptides would presumably involve movement via intercellular spaces or receptor-mediated endocytosis (Einer-Jensen, 1988), and could be altered by changes in vascular permeability and transport systems regulated by ovarian hormones, as in the endometrium.

In either case, transfer would be enhanced by the extensive area of contact between the surface of the coiled ovarian artery and the ovarian venous blood, and the relatively small distance involved for diffusion or more specific modes of transport. The distance between ovarian venous and arterial blood (i.e. the total thickness of the 'wall' of the ovarian artery) was measured by eyepiece graticule in sections of various adult Pteropus tracts that had been fixed in Bouin's fluid following simple dissection after killing by overdose of anaesthetic. The minimum distance varied from 20 to $75 \mu \mathrm{m}$ (mean $=44.4 \mu \mathrm{m}$ ) and the maximum from 40 to $100 \mu \mathrm{m}$ (mean $=73.9 \mu \mathrm{m}$ ). There was no systematic difference between measurements taken in sections cranial or caudal to the coil or in mid-coil.

Such measurements give only a crude estimate of cross-wall diffusion distance, since the tissues are subject to substantial fixation shrinkage and wall thickness would vary in vivo with changing arterial blood pressure. These estimates are quoted for comparison with the data of Bendz et al. (1982a), who found the average distance between venous and arterial lumina to be approximately $100 \mu \mathrm{m}$ in histological sections of the human ovarian pedicle, where they propose countercurrent transfer of hormones to occur. The Pteropus ovarian vascular complex might also recirculate and concentrate hormones locally, as proposed for the ovarian vasculature of sheep (Walsh et al., 1979) and women (Bendz et al., 1982b). Recirculation in this way might be a mechanism to regulate follicle growth, ovulation and luteal function (Bendz et al., 1982a, b).

Reynolds (1948, 1950) proposed that the arterial spirals or coils seen within the ovarian hilus of rabbits and humans might have multiple functions, such as accommodating changes in ovarian size with normal follicular development and maturation, or regulating intraovarian blood pressure. Thus, the coiled ovarian artery and ovarian vascular complex of Pteropus may perform diverse roles, including local countercurrent transfer from ovary to ipsilateral uterus and vice versa, local hormone recirculation and concentration, and pulse attenuation. The anatomy of the complex would also allow regulation of bloodflow to the uterus and placenta by ovarian vasoactive secretions acting on the ovarian arterial coil. The significance of the small branch of the ovarian artery (artery b. Figs 2-4) that appeared to bypass the coil and lie outside the venous sinus on the left side of four vascular cast preparations remains obscure.

Members of the megachiropteran genus Rousettus display unilateral endometrial growth dependent on the corpus luteum (Gopalakrishna and Karim, 1971), and Bernard (1988) reported 
an 'ovarian rete arteriosum' in $R$. aegyptiacus. His description, based on serial sections, indicates an ovarian-uterine vasculature similar to that of Pteropus, although he states that the ovarian artery appears to 'lie apposed' to the ovarian-uterine veins. A Pteropus-like encapsulated ovary with segregated primordial follicles and ovarian vascular complex, with coiled ovarian artery enclosed in an ovarian venous sinus, has been found to be present in each of nine representative species from nine megachiropteran genera, including the Indian fruit-bat Rousettus leschenaulti (C. S. T. Pow and L. Martin, unpublished). In contrast, no evidence of similar structures in six microchiropteran species from six families could be found, nor in the many reports of microchiropteran and other mammalian ovaries. We postulate that the unusual ovarian anatomy and associated vasculature described for Pteropus is unique to Megachiroptera and is a definitive characteristic of this mammalian suborder. This feature is relevant in the discussion of the phylogeny of the Chiroptera, and in particular whether the Megachiroptera evolved separately from the Microchiroptera and from an early branch of the primate lineage (Pettigrew et al., 1989).

The authors thank the University of Queensland for the postgraduate research scholarship awarded to C. S. T. Pow, the Australian Research Council, which has provided generous long-term support for our research into Australian flying foxes (ARGS grant, D18315556R; ARC grant, A08931916), the personnel of the Queensland Department of Primary Industries, who have provided free food for our captive bats for many years, P. Towers and J. Kennedy for the material used in Fig. 5e and $f$, respectively, and L. Little who cared for all our captive flying foxes.

\section{References}

Baker JR and Baker $Z$ (1936) The seasons in a tropical rain forest (New Hebrides). Pt. 3. Fruit Bats (Pteropodidae) Journal of the Linnean Society (Zoology) 40 123-142

Bernard RTF (1988) An ovarian rete arteriosum may facilitate reproductive asymmetry in the Egyptian fruit bat (Rousettus aegyptiacus) South African Journal of Science 84 856-857

Bendz A, Hansson H-A, Svendsen P and Wiqvist N (1982a) On the extensive contact between veins and arteries in the human ovarian pedicle Acta Physiologica Scandinavica 115 179-182

Bendz A, Lundgren O and Hamberger L (1982b) Countercurrent exchange of progesterone and antipyrine between human utero-ovarian vessels, and of antipyrine between the femoral vessels in the cat Acta Physiologica Scandinavica $114611-616$

Clark BF (1973) Uptake and metabolism of $[1,2-3 \mathrm{H}]$-progesterone injected intraluminally into the uteri of spayed mice Journal of Endocrinology 58 535-562

Clark BF (1974) The effect of oestrogen priming on the uptake, metabolism and biological activity of progestins in the mouse uterus Joumal of Endocrinology 63 343-349

Clark BF (1975) Effect of oestrogen priming on the pattern of progesterone metabolism in the mouse uterus Journal of Endocrinology 66 293-294
De Bonilla H and Rasweiler JJ IV (1974) Breeding activity, preimplantation development, and oviduct histology of the short-tailed fruit bat, Carollia, in captivity Anatomical Record 179 385-404

Einer-Jensen N (1988) Countercurrent transfer in the ovarian pedicle and its physiological implications Oxford Reviews of Reproductive Biology 10 348-381

Gopalakrishna A and Karim KB (1971) Localized progestational endometrial reaction in the uterus of the Indian fruit-bat, Rousettus leschenaulti (Desmaret) Current Science 18 490-491

Gopalakrishna A and Murthy KVR (1960) Utero-ovarian junction in two species of bats Bulletin of the Zoological Society of the College of Science, Nagpur 3 19-22

Land RB, Baird DT and Scaramuzzi RJ (1976) Dynamic studies of prostaglandin $\mathrm{F}-2 \alpha$ in the utero-ovarian circulation of the sheep Journal of Reproduction and Fertility 47 209-214

Lee CS and O'Shea JD (1977) Observations on the vasculature of the reproductive tract in some Australian marsupials Joumal of Morphology $\mathbf{1 5 4}$ 95-114

McCracken JA, Carlson JC, Glew ME, Goding JR, Baird DT, Green K and Samuelsson B (1972) Prostaglandin F2 $\alpha$ identified as a luteolytic hormone in sheep Nature (New Biology) 238 129-134

Marshall AJ (1948) The breeding cycle of an equatorial bat (Pteropus giganteus of Ceylon) Proceedings of the Linnean Society of London 159 103-111

Marshall AJ (1949) Pre-gestational changes in the giant fruit bat (Pteropus giganteus) with special reference to an asymmetric endometrial reaction Proceedings of the Linnean Society of London $16126-36$

Marshall AJ (1953) The unilateral endometrial reaction in the giant fruit bat (Pteropus giganteus Brunnich) Journal of Endocrinology 9 42-44

Martin L, Towers PA, McGuckin MA, Little L, Luckoff $H$ and Blackshaw AW (1987) Reproductive biology of flying foxes (Chiroptera: Pteropodidae) Australian Mammalogy 10 115-118

Nelson JE (1963) Biology of the flying fox (genus Pteropus) in south-eastern Queensland $\mathrm{PhD}$ Thesis, University of Queensland

Pettigrew JD, Jamieson BGM, Robson SK, Hall LS, McNally KI and Cooper HM (1989) Phylogenetic relations between microbats, megabats and primates (Mammalia: Chiroptera and Primates) Philosophical Transactions of the Royal Society of London Series B $\mathbf{3 2 5} 489-559$

Pow CST and Martin L (1987) Asymmetric endometrial development in flying foxes (Pteropus spp) may be explained by local counter-current hormone exchange Proceedings of the Australian Society for Reproductive Biology 19100

Rasweiler JJ IV (1972) Reproduction in the long-tongued bat, Glossophaga soricina I Preimplantation development and histology of the oviduct Journal of Reproduction and Fertility 31 249-262

Rasweiler JJ IV (1978) Unilateral oviductal and uterine reactions in the little bulldog bat, Noctilio albiventris Biology of Reproduction 19 467-492

Reynolds SRM (1948) Morphological determinants of the flow-characteristics between an artery and its branch, with special reference to the ovarian spiral artery in the rabbit Acta Anatomica 5 1-16

Reynolds SRM (1950) The vasculature of the ovary and ovarian function Recent Progress in Hormone Research 5 65-100

Towers PA and Martin L (1985) Some aspects of female reproduction in the grey-headed flying-fox, Pteropus poliocephalus (Megachiroptera: Pteropodidae) Australian Mammalogy 8 257-263

Von der Borch SM (1963) Unilateral hormone effect in the marsupial Trichosurus vulpecula Journal of Reproduction and Fertility 5 447-449

Walsh SW, Yutrzenka GJ and Davis JS (1979) Local steroid concentrating mechanism in the reproductive vasculature of the ewe Biology of Reproduction $201167-1171$

Wimsatt WA (1975) Some comparative aspects of implantation Biology of Reproduction 12 1-40

Wimsatt WA (1979) Reproductive asymmetry and unilateral pregnancy in Chiroptera Journal of Reproduction and Fertility 56 345-357 